\title{
Proximal Humeral Fractures: A Review of Current Concepts
}

\author{
James C. Widnall ${ }^{1}$, Sujay K. Dheerendra ${ }^{1}$, Joby Jacob George Malal ${ }^{*}, 2$ and Mohammed Waseem ${ }^{2}$ \\ ${ }^{1}$ Aintree University Hospitals NHS Trust, Longmoor Lane, Liverpool, L9 7AL, UK \\ ${ }^{2}$ Macclesfield District General Hospital, Victoria Road, Macclesfield, Cheshire, SK10 3BL, UK
}

\begin{abstract}
The majority of proximal humerus fractures are sustained via low energy falls in the elderly population. These patients can attain an acceptable level of function via non-operative treatment. There is yet to be a clear consensus on treatment options suitable for those that fall outside of this majority group. Open reduction internal fixation, intra medullary nailing and arthroplasty surgery have all been used to varying effects. Good results are achievable if complications such as mal-union, non-union and avascular necrosis can be avoided. This review aims to clarify the options available to the current day trauma surgeon.
\end{abstract}

Keywords: Fractures, internal fixation, osteosynthesis, proximal humerus.

\section{INTRODUCTION}

Proximal humeral fractures are witnessed mainly in the elderly population, with the highest prevalence being 405 per 100,000 in those patients aged over 70 years [1-3]. They are usually preceded by a low energy fall and for those that are minimally displaced conservative treatment yields positive results with return to a functional shoulder $[4,5]$. It has been quoted that approximately $20 \%$ of proximal humeral fractures require operative intervention [6]. It is still unclear however the best modality in which to perform definitive treatment in order to maximise the return to function. Both reconstructive and reparative options continue to evolve, each with various advantages and associated complications. The aim of this review is to understand current concepts with regards to treatment options for fractures of the proximal humerus.

\section{ASSESSMENT}

As with all patients in the acute setting, a thorough clinical assessment is required to avoid any impending pitfalls. A clear history of mechanism of injury should be sought. A moment should be spared to consider any causative factors behind a seemingly simple trip or fall in this frail, elderly population. Further questioning and pertinent medical investigation may reveal underling neurological or cardiovascular pathology. Ascertaining the patient's pre morbid activity level and level of expectations is important when considering treatment options. Handedness, occupational status, hobbies and level of daily activity should also be taken into account.

Examination of the injured limb is also of great importance. Open fractures are rare, despite the usual poor skin condition of this patient group. Nonetheless, skin tenting and impending necrosis should be evaluated for and

*Address correspondence to this author at the Department of Orthopaedics, Macclesfield District General Hospital, Victoria Road, Macclesfield, Cheshire, SK10 3BL, UK; Tel: +44 1625 661315; Fax: +44 1625 425873; E-mail: jjgeorgemalal@gmail.com treated accordingly. An associated dislocation of the humeral head can occur in this injury and may be diagnosed clinically by the typical anterior protrusion of the humeral head. Neurovascular status needs to be examined and recorded carefully. Tractional injuries to the axillary nerve and brachial plexus can occur, more commonly with concomitant dislocation [7-9]. The deficit is normally treated conservatively although early exploration has been advocated in the younger population [10].

\section{CLASSIFICATION}

There is yet to be a definitive, easily used classification for proximal humeral fractures. Charles Neer's system from 1970 [11, figure 1] is still the most widely used. The crux of this system is based around the bony anatomy of the proximal humerus defined by Codman in the 1930s [12]. He subdivided the proximal humerus into four major areas; 1) humeral head superior to the anatomical neck, 2) lesser tuberosity, 3) greater tuberosity and 4) diaphyseal shaft of the humerus [12, figure 2]. Neer expanded on this system with the addition of displacement of aforementioned fragments, with the displacement considered significant if the fragment had moved by $>10 \mathrm{~mm}$ or rotated through $<45^{\circ}$. $\mathrm{He}$ then further subdivided his work by the concept of dividing the fracture type into the number of parts. For example, a lesser tuberosity fracture may be involved in a two, three or four part fracture, with or without the presence of a dislocated glenohumeral joint. Unfortunately it has been shown to exhibit both poor inter and intra observer reliability [13].

Müller has also presented a classification of proximal humeral fractures [14, figure 3]. Realising the importance of the blood supply to the proximal humerus his classification relies on differentiating between fractures proximal and distal to the anatomical neck. Similar to the blood supply of the proximal femur, that of the proximal humerus is notoriously precarious, and if compromised can lead to avascular necrosis (AVN). The main blood supply arises from the anterior humeral circumflex artery which feeds the 
arcuate artery. The arcuate artery perfuses the humeral head proximal to the anatomical neck and does so by entering the bone on the inferior aspect of the head. If this artery was to be avulsed, the viability of the head could not be maintained by either the branches of the posterior humeral circumflex artery or by those perforating through the rotator cuff and AVN would ensue.

To use this classification, one starts by identifying fractures that are extraarticular/at the level of the surgical neck, or intra articular/level of the anatomical neck (type C). Those that are extra articular are then divided into unifocal (type A) or bifocal (type B). Each class is than further subdivided as below;

- Type A (extraarticular, unifocal);

$\circ$ Tuberosity fracture

- Impacted metaphyseal

- Non impacted metaphyseal

- $\quad$ Type B (extraarticular, bifocal);

- With impaction

$\circ$ Without impaction

- With glenohumeral dislocation

- Type C (intraarticular);
○ Displaced
- Impacted
- Dislocated

\section{DECISION MAKING}

Decisions over which treatment modality is best suited to attaining a favourable outcome with regards to proximal humeral fractures are difficult and multi faceted. Previously classification and X-ray interpretation used to be the mainstay of the decision making process. Due to poor intra observer reliability secondary to imperfect classification systems this decision making process is now obsolete [1316].

There are some absolute indications for theatre; those with open fractures, vascular injuries, neurological damage that warrants exploration and/or repair, pathological fractures, three or four part fracture dislocations and true 'head-splitting' fractures [17]. These are however the minority and up to $80 \%$ of proximal humeral fractures are undisplaced, secondary to low energy trauma, and exhibit low risk of mal-union, non-union, AVN and an eventual poor outcome $[18,19]$. These are best treated with non operative management.

Contention arises in the remaining few patients. Various options are available when it comes to surgical intervention. Minimally invasive, plating, nailing and arthroplasty techniques have all been advocated. Surgery is generally aimed at patients who have expectations higher than what can feasibly be achieved by conservative management. These people tend to be younger and lead more active lives. Surgery is also used to avoid, or decrease the risk of nonunion and mal-union. It is important to forewarn the patient that the shoulder would never regain the pre injury levels of function irrespective of the treatment methodology.

\section{NON OPERATIVE TREATMENT}

Non-operative management is best suited to those fractures which have a high chance of union and will be amenable to an adequate outcome for each specific patient. These fractures are commonly those in a stable configuration and which exhibit minimal displacement $\left(<30^{\circ}\right.$ varus/valgus angulation of the diaphyseal shaft in relation to the humeral head) [15]. Conservative management routinely consists of a brief period of immobilisation in a sling like manner in order to attain adequate pain control prior to mobilisation under the guidance of physiotherapists [20]. It is common for patients to find comfort in resting in the sitting position and this may even extend to times of sleep, particularly early on in the fracture healing process. It should be reiterated to patients and associated carers alike that prolonged periods of immobility are detrimental to the outcome. Some sort of physiotherapy should be initiated by two weeks post injury $[21,22]$. Physiotherapy normally consists of simple pendulum movements in the early stages progressing onto vertical wall walks once symptoms allow. The perils of nonunion, symptomatic mal-union and avascular necrosis of the humeral head are the main protagonists in preventing a positive outcome.

\section{OPERATIVE TREATMENT}

The primary aim of operative fixation is to restore function to the reasonable level of expectation from the patient. In order for this outcome to occur, congruency must be restored between humeral head and its shaft, along with anatomical reduction of the tuberosities and their related cuff attachments. Infection, non-union and metalwork failure are the common complications associated with operative intervention.

\section{Minimally Invasive/Closed Reduction and Percutaneous Fixation}

The obvious advantage of this technique is minimal soft tissue dissection when compared to other types of operations. This decreases risk of avascular necrosis, nonunion, blood loss, post operative pain and infection. It also allows for improved cosmesis and some would argue faster post-operative physiotherapy due to minimal scar tissue formation [23]. The fracture is reduced under image guidance and held with the use of either Kirschner wires or srews [23-26]. This technique has a steep learning curve, however, good results have been demonstrated using both closed and mini open techniques [27, 28]. A sound understanding of the surrounding anatomy is essential as damage to axillary nerve, cephalic vein, long head of biceps tendon and posterior circumflex humeral artery has been previously documented [29].

\section{Open Reduction Internal Fixation}

The evolution of reduction techniques, implants and grafting methods have greatly enhanced the therapeutic scope of operative fixation. Plate and screw design, with multi-directional locking options can now withstand extreme pull out forces. The anterior deltopectoral approach is still the workhorse of this operative technique [30]. Exposure for comminuted fractures, particularly those including the posterior aspect of the humeral head, can also utilise the extended transdeltoid approach [31, 32]. Anatomical reduction is usually aided by a preoperative CT scan of the injured region. Particular attention should be paid to the medial calcar due to both its importance in maintaining 
blood supply to the head and fracture stability [33,34]. The plate should be sited inferiorly enough to avoid postoperative impingement and superiorly enough to ensure correct placement of the head screws [34]. Articular penetration of these proximal screws should be avoided. Bone graft either with autograft, allograft or bone substitute can add to the stability of the overall construct and promote bony healing [35-37]. Reduction of the tuberosities should not be overlooked in order to regain biomechanical advantage of the rotator cuff and increase the strength of the fixation.

Results are difficult to compare between the various plate types as outcome measures in the published literature have been inconsistent [38]. Those who are under the age of 60 years or those whom sustain 2 or 3 part fractures tended to have an improved functional outcome compared to the older age group and more comminuted fracture types [39-44]. The major complications are those of screw perforation (8.5\%), AVN (5.1\%), implant failure (3.15\%) and impingement (3.1\%) [39].

\section{Intra Medullary Nailing}

Intramedullary nailing is mostly suited to 2 part surgical neck fractures $[45,46]$. Results are significantly poorer in those with 3 or 4 part fractures [47-49]. Some surgeons are reticent about intra medullary nailing in the younger patient due to reported rotator cuff damage and persistent shoulder pain [47]. This can be minimized by meticulous placement of the entry point avoiding the footprint of the supraspinatus tendon. Ensuring the nail is well buried under the bone also helps prevent post-operative discomfort and subsequent need for nail removal [50, 51].

\section{Arthroplasty Surgery}

Neer endorsed the use of arthroplasty for 3 or 4 part fractures in response to the high rates of non-union and AVN seen with early plating techniques [52]. The recent advances in plate fixation methods have significantly reduced the rates of the complications, thus lessening the need for head replacing surgery. However, there is undoubtedly still a role to be played by arthroplasty surgery in proximal humerus fractures. Those patients in whom humeral head is not amenable to anatomical reduction and those where soft tissue inadequacies or fracture geometry will undoubtedly result in AVN will benefit from replacement surgery.

In the acute setting, hemiarthroplasty is traditionally preferred to total shoulder replacement [53,54]. By restoring correct head height, version and offset, satisfactory results are attainable. Yet again, the restoration of the tubercles has been proven imperative to an adequate outcome $[55,56]$. As with IM nailing, the younger populous perform functionally better in the post operative period $[57,58]$. These prostheses are normally cemented in order to account for the effects of osteoporosis. Both hemiarthroplasty and total shoulder replacements require a functioning rotator cuff mechanism for acceptable medium to long term function. There would be a small group of elderly patients with three and four part proximal humeral fractures where this cannot be reasonably expected. This has led to the use of reverse shoulder arthroplasty in this sub goup. Early results of reverse shoulder arthroplasty are encouraging, but longer term results and results from larger study groups would be required before the technique could be more widely offered [59-61].

\section{COMPLICATIONS}

A favourable outcome is generally achieved if the complications of AVN, non-union and tuberosity mal-union can be avoided. These can be sequelae of either the original injury or subsequent management.

AVN is more commonplace in comminuted fractures. Any associated dislocation also increases the risks of impairment of vascular supply to the humeral head. As previously mentioned, the inferomedial portion of the head is believed to be a critical area with regards to maintaining adequate blood supply. Pain and loss of function are commonly seen in those patients who develop AVN. Plain radiographs may show changes somewhere on a spectrum between sclerotic patches to collapse and resorption of the affected bone. MRI is commonly used to further evaluate the extent of damage. Core decompression has been advocated in early disease however most require humeral head replacement [62, 63].

The normal contributory factors for non-union apply to proximal humeral fractures as well, such as infection, poor physiological reserve, smoking, diabetes, inadequate fracture stabilisation and excessive soft tissue stripping [64-66]. Radiographs may show the non union but a computed tomogram may be required for confirmation. If a non-union is present, either shoulder arthroplasty or ORIF with bone grafting is usually required.

Mal-union is common after these fracutes. The elderly population tend to cope well, undoubtedly due to lower expectations/ demand. Younger patients would notice a decrease in function, particularly when the tuberosities and their adjoining cuff insertions are involved. Again, radiographs may show evidence of mal-union but a CT will confirm the diagnosis, as well as proving useful information for preoperative planning. Both arthroplasty and corrective osteotomies are widely used to treat the problem.

Though some amount of stiffness is expected after these fractures, any significant limitation should be investigated and treated. Capsular tightness, fracture mal-union, impingement secondary to plate misplacement and cuff dysfunction can all contribute to a stiff shoulder. Physiotherapy is the mainstay of treatment with manipulation under anaesthesia and arthroscopic adhesiolysis providing relief in resistant cases.

\section{CONCLUSIONS}

Nearly $80 \%$ of proximal humeral fractures are from low energy trauma in an elderly population with low expectations. These are best served with non-operative management while encouraging early restoration of functional movement. Those fractures that have significant displacement especially in the younger age group would benefit from internal fixation techniques. Those who are at high risk of AVN of the humeral head or have sustained such gross comminution that head anatomy or cuff function is unlikely to be restored will benefit from arthroplasty surgery. 


\section{CONFLICT OF INTEREST}

The authors confirm that this article content has no conflict of interest.

\section{ACKNOWLEDGEMENTS}

Declared none.

\section{REFERENCES}

[1] Court-Brown CM, Garg A, McQueen MM. The epidemiology of proximal humeral fractures. Acta Orthop Scand 2001; 72: 365-71.

[2] Kannus P, Palvanen M, Niemi S, et al. Osteoporotic fractures the proximal humerus in elderly Finnish persons: sharp increase in 1970-1998 and alarming projections for the new millennium. Acta Orthop Scand 2000; 71: 465-70.

[3] Bengner U, Johnell O, Redlund-Johnell I. Changes in the incidence of fracture of the upper end of the humerus during a 30-year period: a study of 2125 fractures. Clin Orthop 1988; 231: 179 - 82.

[4] Horak J, Nilsson BE. Epidemiology of fracture of the upper end of the humerus. Clin Orthop Relat Res 1975; (112): 250-3.

[5] Lind T, Kroner K, Jensen J. The epidemiology of fractures of the proximal humerus. Arch Orthop Trauma Surg 1989; 108(5): 285-7.

[6] Maravic M, Le Bihan C, Landais P, Fardellone P. Incidence and cost of osteoporotic fractures in France during 2001. A methodological approach by the national hospital database. Osteoporos Int 2005; 16: 1475-80.

[7] De Laat EA, Visser CP, Coene LN, Pahlplatz PV, Tavy DL. Nerve lesions in primary shoulder dislocations and humeral neck fractures: a prospective clinical and EMG study. J Bone Joint Surg Br 1994; 76: 381-3.

[8] Visser CP, Coene LN, Brand R, Tavy DL. Nerve lesions in proximal humeral fractures. J Shoulder Elbow Surg 2001; 10: 4217.

[9] Visser CP, Tavy DL, Coene LN, Brand R. Electromyographic findings in shoulder dislocations and fractures of the proximal humerus: comparison with clinical neurological examination. Clin Neurol Neurosurg 1999; 101: 86-91.

[10] Fox M, Lambert S, Birch R. The terrible triad of the shoulder. J Bone Joint Surg Br 2009; 91-B(Suppl 1): 13.

[11] Neer CS 2nd. Displaced proximal humeral fractures. I: classification and evaluation. J Bone Joint Surg Am 1970; 52-A: 1077-89.

[12] Codman AE. The shoulder. Boston, Massachusetts: Thomas Todd Co 1934 ; p. 319.

[13] Sidor ML, Zuckerman JD, Lyon T, et al. The Neer classification system for proximal humeral fractures: an assessment of interobserver reliability and intraobserver reproducibility. $\mathrm{J}$ Bone Joint Surg Am 1993; 75-A: 1745-50.

[14] Müller ME, Nazarian S, Koch $\mathrm{P}$, et al. The Comprehensive Classification of Fractures of Long Bones. $1^{\text {st }}$ ed. Berlin, Heidelberg, New York: Springer-Verlag 1990.

[15] Court-Brown CM, Cattermole H, McQueen MM. Impacted valgus fractures (B1.1) of the proximal humerus. The results of nonoperative treatment. J Bone Joint Surg Br 2002; 84(4): 504-8.

[16] Robinson CM, Akhtar A, Mitchell M, Beavis C. Complex posterior fracture-dislocation of the shoulder. Epidemiology, injury patterns, and results of operative treatment. J Bone Joint Surg Am 2007; 89(7): 1454-66.

[17] Murray IR, Amin AK, White TO, Robinson CM. Proximal humeral fractures: current concepts in classification, treatment and outcomes. J Bone Joint Surg Br 2011; 93(1): 1-11.

[18] Tejwani NC, Liporace F, Walsh M, et al. Fucntional outcome following one-part proximal humeral fractures; a prospective study. J Shoulder Elbow Surg 2008; 17(2): 216-9.

[19] Turhan E, Aksoy C, Ege A, et al. Sagittal plane analysis of the open and closed methods of children with discpace supracondylar fractures of the humerus (a radiological study). Arch Orthop Trauma Surg 2008; 128(7): 739-44.

[20] DePalma AF, Cautilli RA. Fractures of the upper end of the humerus. Clin Orthop 1961; 20: 73-93.

[21] Koval KJ, Gallagher MA, Marsicano JG, et al. Functional outcome after minimally displaced fractures of the proximal part of the humerus. J Bone Joint Surg Am 1997; 79(2): 203-7.

[22] Kristiansen B, Angermann P, Larsen TK. Functional results following fractures of the proximal humerus. A controlled clinical

study comparing two periods of immobilization. Arch Orthop Trauma Surg 1989; 108(6): 339-41.

[30] Neer CS 2nd, Watson KC, Stanton FJ. Recent experience in total shoulder replacement. J Bone Joint Surg Am 1982; 64-A: 319-37.

[31] Gardner MJ, Boraiah S, Helfet DL, Lorich DG. The anterolateral acromial approach for fractures of the proximal humerus. J Orthop Trauma 2008; 22: 132-7.

[32] Robinson CM, Khan L, Akhtar A, Whittaker R. The extended deltoid-splitting approach to the proximal humerus. J Orthop Trauma 2007; 21: 657-62.

[33] Hertel R, Hempfing A, Stiehler M, Leunig M. Predictors of humeral head ischemia after intracapsular fracture of the proximal humerus. J Shoulder Elbow Surg 2004; 13(4): 427-33.

[34] Gardner MJ, Weil Y, Barker JU, et al. The importance of medial support in locked plating of proximal humerus fractures. J Orthop Trauma 2007; 21(3): 185-91.

[35] Robinson CM, Wylie JR, Ray AG, et al. Proximal humeral fractures with a severe varus deformity treated by fixation with a locking plate. J Bone Joint Surg Br 2010; 92-B: 672-8.

[36] Gerber C, Werner CM, Vienne P. Internal fixation of complex fractures of the proximal humerus. J Bone Joint Surg Br 2004; 86B: 848-55.

[37] Russo R, Visconti V, Lombardi LV, Ciccarelli M, Giudice G. The block-bridge sys- tem: a new concept and surgical technique to reconstruct articular surfaces and tuberosities in complex proximal humeral fractures. J Shoulder Elbow Surg 2008; 17: 29-36.

[38] Dheerendra SK, Khan WS, Barber J, Goddard NJ, Ahrens PM. Outcomes of locking plates in proximal humeral fractres: a systematic review. Shoulder Elbow 2011: 3: 74-84.

[39] Handschin AE, Cardell M, Contaldo C, Trentz O, Wanner GA. Functional results of angular-stable plate fixation in displaced proximal humeral fractures. Injury 2008; 39: 306-13.

[40] Klitscher D, Blum J, Andreas D, et al. Osteosynthesis of proxiaml humeral fractures with the fixed angle PHILOS plate. Eur J Trauma Emerg Surg 2008; 34: 29-36.

[41] Koukakis A, Apostolou CD, Taneja T, Korres DS, Amini A. Fixation of proximal humerus fractures using the PHILOS plate: early experience. Clin Orthop Relat Res 2006; 442: 115-20.

[42] Rouleau DM, Laflamme GY, Berry GK, et al. Proximal humerus fractures treated by percutaneous locking plate internal fixation. Orthop Traumatol Surg Res 2009; 95: 56-62.

[43] Bigorre N, Talha A, Cronier P, et al. A prospective study of a new locking plate for proximal humeral fracture. Injury 2009; 40: 1926.

[44] Bjorkenheim J, Pajarinen J, Savolainen V. Internal fixation of proximal humeral fracture with a locking compression plate. A retrospective evaluation of 72 patients followed for a minimum of 1 year. Acta Orthop Scand 2004; 75: 741-5.

[45] Hatzidakis AM, Shevlin MJ, Fenton DL, et al. Angular-stable locked intramedullary nailing of two-part surgical neck fractures of the proximal part of the humerus. A multicenter retrospective observational study. J Bone Joint Surg Am 2011; 93(23): 2172-9.

[46] Zhu Y, Lu Y, Shen J, et al. Locking intramedullary nails and locking plates in the treatment of two-part proximal humeral surgical neck fractures: a prospective randomized trial with a 
minimum of three years of follow-up. J Bone Joint Surg Am 2011; 93(2): 159-68.

[47] Adedapo AO, Ikpeme JO. The results of internal fixation of threeand four-part proximal humeral fractures with the Polarus nail. Injury 2001; 32: 115-21.

[48] Agel J, Jones CB, Sanzone AG, Camuso M, Henley MB. Treatment of proximal humeral fractures with Polarus nail fixation. J Shoulder Elbow Surg 2004; 13: 191-5.

[49] Lin J, Hou SM, Hang YS. Locked nailing for displaced surgical neck fractures of the humerus. J Trauma 1998; 45: 1051-7.

[50] Mittlmeier TW, Stedtfeld HW, Ewert A, et al. Stabilization of proximal humeral fractures with an angular and sliding stable antegrade locking nail (Targon PH). J Bone Joint Surg Am 2003; 85-A(Suppl 4): 136-46.

[51] Park JY, Pandher DS, Chun JY, et al. Antegrade humeral nailing through the rotator cuff interval: a new entry portal. J Orthop Trauma 2008; 22(6): 419-25.

[52] Neer 2nd CS. Displaced proximal humeral fractures. II. Treatment of three-part and four-part displacement. J Bone Joint Surg Am 1970; 52(6): 1090-103.

[53] Fjalestad T, Hole MO, Blucher J, et al. Rotator cuff tears in proximal humeral fractures: an MRI cohort study in 76 patients. Arch Orthop Trauma Surg 2010; 130(5): 575-81.

[54] Gallo RA, Sciulli R, Daffner RH, et al. Defining the relationship between rotator cuff injury and proximal humerus fractures. Clin Orthop Relat Res 2007; 458: 70-7.

[55] Boileau P, Krishnan SG, Tinsi L, et al. Tuberosity malposition and migration: reasons for poor outcomes after hemiarthroplasty for displaced fractures of the proximal humerus. J Shoulder Elbow Surg 2002; 11(5): 401-12.

[56] Frankle MA, Greenwald DP, Markee BA, et al. Biomechanical effects of malposition of tuberosity fragments on the humeral prosthetic reconstruction for four-part proximal humerus fractures. J Shoulder Elbow Surg 2001; 10(4): 321-6.
Robinson CM, Page RS, Hill RM, et al. Primary hemiarthroplasty for treatment of proximal humeral fractures. J Bone Joint Surg Am 2003; 85-A(7): 1215-23

[58] Boileau P, Krishnan SG, Tinsi L, et al. Tuberosity malposition and migration: reasons for poor outcomes after hemiarthroplasty for displaced fractures of the proximal humerus. J Shoulder Elbow Surg 2002; 11: 401-12.

[59] Grassi FA, Murena L, Valli F, Albeiro R. Six-year experience with the Delta III reverse shoulder prosthesis. J Orthop Surg 2009; 17: 151-6.

[60] Klein M, Juschka M, Hinkenjann B, Scherger B, Ostermann PA. Treatment of comminuted fractures of the proximal humerus in elderly patients with the Delta III reverse shoulder prosthesis. J Orthop Trauma 2008; 22: 698-704.

[61] Klein M, Juschka M, Hinkenjann B, et al. Treatment of comminuted fractures of the proximal humerus in elderly patients with the Delta III reverse shoulder prosthesis. J Orthop Trauma 2008; 22(10): 698-704.

[62] Gerber C, Hersche O, Berberat C. The clinical relevance of post traumaticavascu- lar necrosis of the humeral head. J Shoulder Elbow Surg 1998; 7: 586-90.

[63] Doetsch AM, Faber J, Lynnerup N, et al. The effect of calcium and vitamin D3 supplementation on the healing of the proximal humerus fracture: a randomized placebo-controlled study. Calcif Tissue Int 2004; 75: 183-8.

[64] Healy WL, Jupiter JB, Kristiansen TK, White RR. Nonunion of the proximal humerus: a review of 25 cases. J Orthop Trauma 1990; 4: 424-31.

[65] Volgas DA, Stannard JP, Alonso JE. Non-unions of the humerus. Clin Orthop 2004; 419: 46-50.

[66] Rooney PJ, Cockshott WP. Pseudarthrosis following proximal humeral fractures: a possible mechanism. Skeletal Radiol 1986; 15: 21-4.

(c) Widnall et al.; Licensee Bentham Open.

This is an open access article licensed under the terms of the Creative Commons Attribution Non-Commercial License (http://creativecommons.org/licenses/by-nc/3.0/) which permits unrestricted, non-commercial use, distribution and reproduction in any medium, provided the work is properly cited. 